\title{
Design of DC Boost Power Supply Module for Complex Electronic Equipment
}

\author{
Zhonghua Zhang \\ Teaching and research section \\ of Reconnaissance fire \\ adjustment radar faculty. \\ Ordnance military school of \\ Wuhan \\ Wuhan, China \\ 362493371@qq.com
}

\author{
Peng Zhang \\ Teaching and research section \\ of Reconnaissance fire \\ adjustment radar faculty. \\ Ordnance military school of \\ Wuhan \\ Wuhan, China \\ peng@qq.com
}

\author{
Hanao Xia \\ Teaching and research section \\ of Reconnaissance fire \\ adjustment radar faculty. \\ Ordnance military school of \\ Wuhan \\ Wuhan, China \\ hanao@163.com
}

\begin{abstract}
The design of Dc booster circuit has the very vital significance for reliable application of complex electronic equipment, especially for the high pressure part. A DC power supply circuit based on resistance, capacitance and voltage regulator is presented according to the requirement of the power supply voltage in a certain type of radar high voltage sub system. This design meets the requirements of high pressure subsystem for $200 \mathrm{v}$ voltage on the output power. It is verified that the $24 \mathrm{~V}-200 \mathrm{~V}$ DC boost power supply fully meets the requirements of the high voltage system, the whole circuit design is stable and reliable, and the design provides an effective guarantee for the stability of the high voltage system.
\end{abstract}

Key Words-Complex Electronic Equipment; High pressure system;DC boost; Over current protection; Rectifier-Filter

\section{INTRODUCTION}

With the rapid development of information technology and computer technology, radar and other large complex electronic equipment in the construction of national defense information technology has become increasingly widespread, in which the high pressure system is an important part of this type of equipment. However, because of opening and closing according to different situations, the high pressure system is not always working. So, in order to make the high voltage unit work better, reduce equipment loss, a lot of equipment for high voltage sub system set up a line for high-voltage power, that is to select a certain magnitude of the electric pressure as a high-voltage system to ensure the stability of the high voltage system. There are a lot of methods for generating high voltage power line without independent voltage conversion module. The voltage generated by the voltage has the problem such as unstable, the ripple voltage too highly, the lack of protection circuit and so on. For the above problems, this paper presents a design method for the booster dc $24 \mathrm{v}$ to $200 \mathrm{v}$ independent power supply circuit which is composed of basic circuit components, voltage fluctuation sampling filter circuit and over current protection circuit. Then, the output voltage is detected. The test results show that the power supply can provide a stable and controllable $200 \mathrm{~V}$ voltage, and can be automatically protected by over current and so on, which can ensure the stability of the high voltage system of the large complex electronic equipment.

\section{COMPOSITION OF HARDWARE}

In this paper, we design a power supply module which will boost the DC $24 \mathrm{~V}$ to $200 \mathrm{~V}$ according to the requirement for the $200 \mathrm{~V}$ in high voltage system. This circuit has many functions such as DC-AC-DC converter, boost, voltage regulator, over current protection, power control and so on. It is composed of the electric control circuit, the pulse generating circuit, the power amplifier and booster circuits, the rectifier filter circuit, the over current short circuit automatic protection circuit, the voltage fluctuation sampling circuit in the hardware. The composition is shown in figure 1 : 


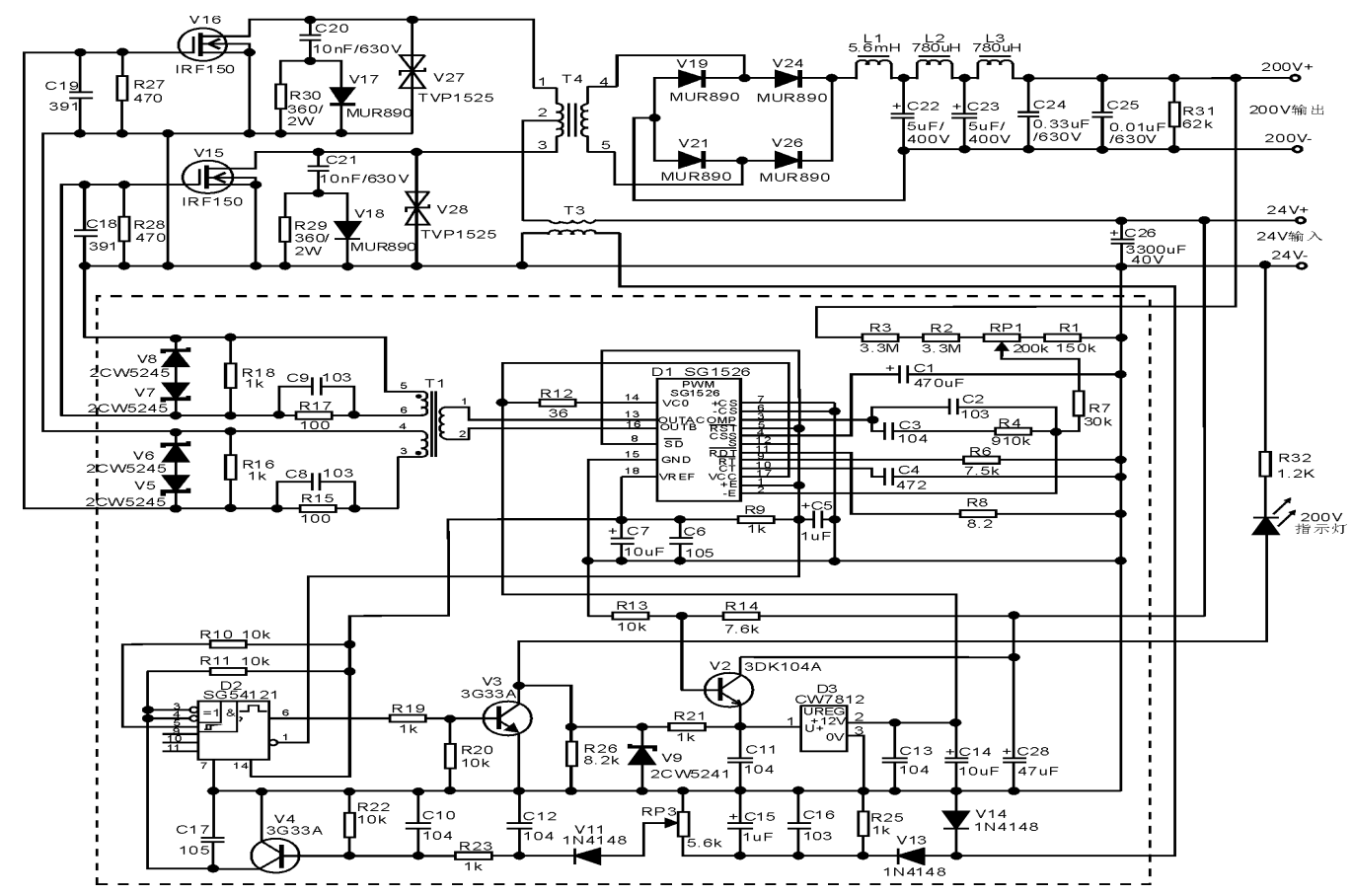

Fig. 1. 24V-200V DC boost circuit diagram

The electric control circuit which can carry out electric control to the input 24 voltage, is composed of the transistor V2 (3 dk104a), three-terminal voltage regulator D3 (2 cw7812 voltage $12 \mathrm{v}$ ), resistance R14, R13, capacitor C11, C13, C14, C28.The pulse generating circuit which can generate the pulse signal with the frequency $22.5 \mathrm{kHz}$, the period $44.4 \mathrm{~s}$ and the pulse width of $19.5 \mathrm{~s}$, is composed of pulse width modulator D1(UC1526/883 b), zener diode V5 and V6, V7 and V8 (2 cw5245 $15 \mathrm{v}$ ) voltage regulator, transformer T1, resistance R6, R9, R12, R15, R16 and R17, R18, capacitor C1, C4, C5, C6, C7, C8, C9.

The power amplifier and booster circuits is composed of the field effect switch tube V15, V16 rf15d (1), diode V17, V18 (MUR090E), transient voltage suppression diodes V27, V28 (TVP1525), transformer T4, resistance R27, the R28, R29, R30, capacitance C18, C19, C20, of C21, C26.The rectifier filter circuit is composed of the diode V19, V21, V24, V26 (MUR090E), filtering inductance L1, L2, L3, filter capacitance C22, C23, C24, C25, resistance of R31.

The over current short circuit automatic protection circuit is composed of over current sampling inductance T3, monostable trigger D2 (SG54121J), triode V4, V3 (3 g33a), voltage regulator tube V9 cw5241 (2), rectifier diode V11, V13, V14 (IN4140), filter capacitor C10, C12, C15, C16, C17, potentiometer RP3, resistance R10, R11, R19, R20, R21, R22, R23, R25, R26.The voltage fluctuation sampling circuit which can carry on the sampling to the voltage fluctuation, the realization of feedback to control the voltage fluctuation, is composed of the potentiometer RP1, resistor R1, R2, R3 and R4, R7, capacitance C2 and C3.

\section{WORKING PRINCIPLE}

\section{A. Dc booster principle}

The DC $24 \mathrm{~V}$ power will be divided into two channels after getting into the power supply circuit. One signal will be sent to the source pole of V15, V16 through the T3 and T4, the other will be sent to the electric control circuit V2.

The pulse width modulator D1 generates the pulse signal with the frequency $22.5 \mathrm{kHz}$, the period $44.4 \mathrm{~s}$ and the pulse width of $19.5 \mathrm{~s}$ in the use of $12 \mathrm{v}$ output voltage from the pin 2 of three-terminal voltage regulator D3, which is generated by the $24 \mathrm{v}$ power supply in the pin 1 which come from the set-emitter of V2 through the base of electric control circuit V2 after the dividing pressure of R14, R13.This signal generates coupling two mutual difference of $180^{\circ}$ phase of periodic pulse signals which are current-limited by R15、R17,limited by V5、V6、V7、 V8 and make the V15、V16 push-pull conduction, cut-off after presenting effect switch tube between gate and drain of them respectively, through transformer $\mathrm{T} 1$ after outputting from pin 13,16 of D1.Then the 200V $\pm 0.5 \mathrm{~V}$ dc voltage will be output stability after the pulsating voltage which is formed in primary of $\mathrm{T} 4$ 
going through the T4 booster, V19, V21, V24, V26 bridge rectifier and L1, C22, L2, C23, L3, C24, C25 triple filter. At last ,the output will be divided into two channels, one of which is the output, the other head of the RP1 makes the circuit after the D1 work normally through the R7, C2, R4, C3.

C20, V17, C21, V18 is not only used to suppress the high frequency interference, but also can be used in forming a loop for the self-induction electromotive force of sudden jump which is created by the T4 primary when the V15, V16 cut-off suddenly, in order to avoid the electromotive force and $24 \mathrm{v}$ external power superposition and burn out the field effect tube V15, V16. While the R29, R30 are used to put off the voltage stored on C21, C20 when power off.V27, V28 have the function of bidirectional voltage surge suppression, which can protect the field effect tube V15, V16, etc, by being used in ac pulse shaping, limiting voltage. While, the V5 and V6, V7 and V8 can carry out the protection for the field effect tube V15, V16 from the gate and drain after being in reverse concatenated, which is different from the V27, V28.

In normal operation, there is no situation of over current and over voltage in the $200 \mathrm{~V}$ power supply and no signal $(<0.3 \mathrm{~V})$ output in secondary pole of over-current sampling coil T3, so, there is no voltage in base of over-current automatic protection circuit V4, that makes the collector have high level (5V), which is sent to the inverse pin 3, 4 of single steady state trigger D2.Then,the $200 \mathrm{~V}$ power output normal because of pulse width modulator D1 normal operation which is made by the high level (5V) which is sent to D1 from the Q inverting output 1 pin. The high level (11V) which came from collector of V3 which is cut-off because of the partial voltage of low level $(0.3 \mathrm{~V})$ from $\mathrm{Q}$ output pin 6 through R20, R19,is the regulator of V9 is sent to the "200V" indicator that is positive for the light emitting diode, and the indicator light is on, indicating that the out of this power supply module is normal $200 \mathrm{~V}$.

\section{B. Voltage regulation principle}

The sampling voltage is taken out from the center head of the sampling circuit RP1 for the voltage fluctuation when the output DC voltage amplitude of $200 \mathrm{~V}$ has a fluctuation and is greater one of which is sent to sampling circuit R1, R2, R3 and RP1 for voltage fluctuation whose normal sampling voltage $5 \mathrm{v}$ which is taken out by the center

than 0.5V.Then,this sampling voltage is sent to D1 through R7、C2、R4、C3, which can change the conduction time of V15 and V16 by changing the pulse width of the oscillation signal. At last, the output voltage can be obtained with the range of $200 \mathrm{~V} \pm 0.5 \mathrm{~V}$ stably.

\section{Automatic protection principle}

The secondary of T3 will output the pulse induction signal $(>12 \mathrm{~V})$ of over-current rapidly because of the sudden over-current of $200 \mathrm{~V}$ power supply due to the failure of the external load circuit, or the power supply circuit fault. The power and its external load will be protected because the circuit has been stopped working without $200 \mathrm{~V}$ power output, that is realized through making the pulse width modulator D1 stop oscillation by the low level $(0.2 \mathrm{~V})$ came from 1 pin of $\mathrm{Q}$ inverting output which is input from inverting input 3 and 4 pin of single steady state trigger D2 which is the low level signal output from the collector of the transistor V4 whose conduction is caused of the pulse induction signal which is sent to the base of V4 through RP3、 V11、R23 after V13, V14 rectifier and C15, C16 filtering. While, the "200V" indicator light goes out because of the low level came from the collector of V3 after the conduction because of the partial voltage of high level $(>3.5 \mathrm{~V})$ on the base of $\mathrm{V} 3$ through R19、R20,that can indicate that the power supply circuit is fault without $200 \mathrm{~V}$ power output.

\section{PERFORMANCE TEST}

The output voltage amplitude and ripple voltage of the power module are tested after a certain type of radar $24 \mathrm{~V}-200 \mathrm{~V}$ DC boost power supply module has been developed. The test results are shown in Table I and table II.

TABLE. I.THE TEST RESULTS OF OUTPUT VOLTAGE AMPLITUDE

\begin{tabular}{|c|c|c|c|c|}
\hline \multirow{2}{*}{ Test items } & indicator & $\begin{array}{c}\text { Working } \\
\text { time }\end{array}$ & $\begin{array}{c}\text { measured } \\
\text { value }\end{array}$ & conclusion \\
\hline \multirow{4}{*}{$\begin{array}{c}\text { Output voltage } \\
\text { amplitude }\end{array}$} & $200 \mathrm{~V} \pm 2 \mathrm{~V}$ & $5 \mathrm{~h}$ & $200.3 \mathrm{~V}$ & Meet the requirements \\
\cline { 2 - 5 } & $200 \mathrm{~V} \pm 2 \mathrm{~V}$ & $10 \mathrm{~h}$ & $200.1 \mathrm{~V}$ & Meet the requirements \\
\cline { 2 - 5 } & $200 \mathrm{~V} \pm 2 \mathrm{~V}$ & $20 \mathrm{~h}$ & $199.8 \mathrm{~V}$ & Meet the requirements \\
\cline { 2 - 5 } & $200 \mathrm{~V} \pm 2 \mathrm{~V}$ & $50 \mathrm{~h}$ & $200.0 \mathrm{~V}$ & Meet the requirements \\
\cline { 2 - 5 } & $200 \mathrm{~V} \pm 2 \mathrm{~V}$ & $100 \mathrm{~h}$ & $201.2 \mathrm{~V}$ & Meet the requirements \\
\hline
\end{tabular}


TABLE.II.THE TEST RESULTS OF RIPPLE VOLTAGE

\begin{tabular}{|c|c|c|c|c|}
\hline \multirow{2}{*}{ Test items } & indicator & $\begin{array}{c}\text { Working } \\
\text { time }\end{array}$ & $\begin{array}{c}\text { measured } \\
\text { value }\end{array}$ & conclusion \\
\hline \multirow{3}{*}{ Ripple voltage } & $\leq 1 \mathrm{~V}$ & $5 \mathrm{~h}$ & $0.1 \mathrm{~V}$ & Meet the requirements \\
\cline { 2 - 5 } & $\leq 1 \mathrm{~V}$ & $10 \mathrm{~h}$ & $0.2 \mathrm{~V}$ & Meet the requirements \\
\cline { 2 - 5 } & $\leq 1 \mathrm{~V}$ & $20 \mathrm{~h}$ & $0.1 \mathrm{~V}$ & Meet the requirements \\
\cline { 2 - 5 } & $\leq 1 \mathrm{~V}$ & $50 \mathrm{~h}$ & $0.01 \mathrm{~V}$ & Meet the requirements \\
\cline { 2 - 5 } & $\leq 1 \mathrm{~V}$ & $100 \mathrm{~h}$ & $0.4 \mathrm{~V}$ & Meet the requirements \\
\hline
\end{tabular}

\section{CONCLUSION}

This paper introduces and analyzes the main functions, hardware components, working principle and protection circuit of DC boost circuit which be used in high voltage sub system of the complex electronic equipment, and gives a $24 \mathrm{~V}-200 \mathrm{~V}$ DC boost power supply circuit with DC boost, voltage ripple suppression and over-current protection function. At present, this circuit module has been applied in high voltage system in a type of radar and other complex electronic equipment successfully, and with working stably and reliably.

\section{REFERENCES}

[1] JIA Kai, ZHENG Chunhui, CHEN Weilian. Design and implementation of dual power supply circuit based on TMS320F2812[J]. ELECTRONIC ENGINEER, 2008(9) : 21-23.

[2] ZHANG Guang-xin, YANG Geng. Power Supply Design for Controller of Active Power Filter[J]. Power Electronics, 2010(2) : 25-27.

[3] Yujie Fang, Binghua Su, Lingxia Hang. Study on ripple rejection of switching power supply[J]. Modern electronic technology, 2012 (5) : 37-39.

[4] Chen Lin Li Shuqin Lin Hui. Digital Power Management and Power Management Bus[J]. Electric drive, 2008(8) : 19-21.

[5] Lu Qiusheng. Bus technology used in digital power[J].Electronic test, 2009(9) : 35-37. 